\title{
Urban Adaptive Avifauna: A Case Study from Peradeniya, Sri Lanka
}

\author{
Galappaththi H.G.S.S.*, Wijesundara C.S. \\ Department of Zoology, University of Peradeniya, Sri Lanka \\ *ssg9979@gmail.com
}

\begin{abstract}
Urbanisation leads to anthropogenic modifications of natural habitats of bird species. These modifications can cause a change in the community composition of animals, a larger proportion of which would be more adaptable species whereas a smaller proportion would be less adaptable species. The bird species that show a positive response to urbanization and primarily dependent upon human influenced variables for food, habitat, dispersal, etc., are known as full synanthropes or urbanophiles. The objective of present study was to study the adaptability of avifauna towards urbanization through synanthropy. The study was conducted from December 2015 to August 2016, in two sites in Peradeniya, i.e., Hanthana and Gannoruwa, covering three habitat types which represent an urbanization gradient. Two belt transects were laid starting from urban habitat to forest habitat. Statistical analyses were done using MS Office Excel 2010 and PRIMER 7 Software. Bubble plots on abundance and distribution of identified, commonly known urbanophilic species showed a distribution restricted only to forest edge, suburban and urban habitats and their absence in forest core habitat. These urbanophilic bird species included Large-billed Crow (Corvus macrorhynchos), House Crow (Corvus splendens), Common Myna (Acrido theres tristis), Yellow-billed Babbler (Turdoides affinis), Rock Pigeon (Columba livia), House Sparrow (Passer domesticus), Oriental Magpie Robin (Copsychus saularis), Pale-billed Flower pecker (Dicaeum erythrorhynchos), Purple-rumped Sunbird (Leptocoma zeylonica), and Long Billed Sunbird (Cinnyris lotenius). The proportion of urbanophilic individuals were $55.29 \%$, $81.70 \%, 51.97 \%$ and $66.81 \%$ in Hanthana-suburban, Hanthana-urban, Gannoruwa-suburban and Gannoruwa-urban habitats respectively. These species were observed feeding on human influenced food variables in garbage dumping areas, bird feeders, ornamental or cultivated plants, etc. Most of the identified urbanophiles in this study were omnivorous, grainivorous, insectivorous or nectarivorous species. Furthermore, species that exclusively feed on seeds such as the Rock Pigeon were present only in urban habitats. Apart from feeding, they were using human-made structures and trees in parks in urban matrix for perching and sometimes for nesting as well. However, urbanization favors habitat generalists and it suppresses habitat specialists; hence omnivores are more abundant in modified habitats. Food provided by humans has a major impact on bird community. These urbanophiles tend to be opportunistic feeders according to food availability and hence they tend to exploit new food sources. As a result, availability of food and habitats in urbanized environments strongly favor few groundfeeding or omnivorous bird species such as House Crow and Common Myna.
\end{abstract}

Keywords: Urbanisation, Syananthropy, Adaptability, Resources, Opportunistic

Proceedings of the $22^{\text {nd }}$ International Forestry and Environment Symposium 2017 of the Department of Forestry and Environmental Science, University of Sri Jayewardenepura, Sri Lanka 